\title{
THREE YEARS FOLLOW UP STUDY OF THE EFFECT OF IMPLANT ABUTMENT CONNECTION ON BONE RESORPTION AROUND IMPLANTS PLACED AT DIFFERENT CRESTAL LEVELS
}

\author{
Ahmed M. Alam-Eldein* and Tamer M. Nasr Mostafa*
}

\begin{abstract}
Statement of problem: Implant abutment connection may affect the stresses and strains induced at the peri-implant area and influence crestal bone resorption around implants at different levels of crestal placement.

Materials and Methods: Implants were divided into two groups: internal hexagon (Legacy ${ }^{\mathrm{TM}}$ 2, Implant Direct) and conical hybrid connection (AnyRidge; MEGAGEN). Each group was further subdivided into three subgroups depending on the location of surgical placement (subcrestal, crestal, or supracrestal) of the implant platform. Each case was evaluated radiographically and linear measurements of bone resorption were made from the implant's apex to the first point of bone-to-implant contact at prostheses loading and after 6, 12, 24 and 36 months. Data were collected, tabulated and statistically analyzed using $\mathrm{t}$ Student test and ANOVA test followed by Tukey's test.
\end{abstract}

Results: No Statistical significant differences were found between the main tested two groups $(P \geq 0.05)$, however there were statistical significant differences between the position groups with the conical hybrid subcrestal group showing the lowest values of peri-implant bone after three years of prostheses insertion.

Conclusions: Conical hybrid implant abutment connection showed less crestal bone resorption around implants than internal hexagon implant abutment connection in any position of placement. Subcrestal implant surgical positioning showed the less crestal bone resorption followed by supracrestal. Crestal implant positioning should be avoided whenever possible.

KEYWORDS: implant abutment, internal connection, conical hybrid, crestal bone resorption.

\footnotetext{
* Associate Professor, Prosthodontic Department, Faculty of Dentistry, Tanta University
} 


\section{INTRODUCTION}

Till now; implant prosthodontics still introduce a challenge, specially the configuration of the connecting part that allows the abutment to be attached to the implants which are considered one of the features that has been for a long time the object of debate. External hexagon connection was introduced first by Branemark system. ${ }^{1}$ This design has served well for decades and it has been introduced in other competing systems.

Unfortunately, external hexagon showed some drawbacks as it is less favorable for stress distribution, increases the stresses on the abutment screw, induces micro-movements during loading when compared to internal connection which creates a microgap in the implant abutment interface. ${ }^{2}$ This microgap has been considered as a main factor that induces peri-implant crestal bone resorption besides other factors such as surgical trauma during implant insertion, implant design and implant positioning level. ${ }^{3}$

On the other hand, internal connections have been incorporated in the implant systems to eliminate mechanical complications, reduce stresses transferred to the crestal bone and solve the external hexagon design complications, ${ }^{4,5}$ but when analyzing the implant-abutment coupling of internal connecting systems, many differences have been described ${ }^{6-9}$ An important question aroused: What is the impact of implant abutment configuration on crestal bone level changes? Since, unlike the external hexagon connection, the internal connection configurations adopted by different companies are not alike..$^{10,11}$

In previous stress analysis study; the authors found that the stress distribution at the level of the implant abutment connection is strongly associated with the design characteristics of the interface, which may vary according to the manufacturer; which in turn affect the magnitude of stress distribution in the bone surrounding the dental implants, ${ }^{12}$ while clinical follow up studies reveals conflicting results. ${ }^{11}$

Although subcrestal placement of implants is recommended to obtain an excellent emergence profile $^{13}$ and to reduce the strains at the peri-implant bone. ${ }^{14}$ It causes more inflammatory reaction correlated with bone loss than supracrestal position did. ${ }^{15}$ On the other hand; supracrestal positioning has been recommended as it shows lower levels of peri-implant crevicular fluid, and tumor necrosis factor-A around supracrestal positioned implants. ${ }^{16}$

However; clinical comparative studies showed conflicting results concerning the effect of implant placement level on peri-implant crestal bone loss. ${ }^{17-21}$ While Jung et al ${ }^{17}$ reported that the greatest bone loss occurred at implants placed subcrestally; Van Eekeren et al. ${ }^{18}$ concluded that crestal position yielded less bone resorption than supracrestal position. In contrast; some studies showed a positive impact on crestal bone preservation with subcrestal implant placement. ${ }^{19-22}$

\section{AIM OF THE STUDY}

The aim of the current study was to test the hypothesis that implant-abutment configuration has no effect on crestal bone resorption around implants after three years of loading at any surgical position of implant placement.

\section{MATERIALS AND METHODS}

This study was carried out on partially edentulous male patients, with a mean age of 46 years old have received sixty implants. Medical history was taken to evaluate each patient's general health to make sure they were free from any other systemic diseases that might have an effect on implants osseointegration. Laboratory investigations included the Glycosylated Hemoglobin Test (HbA1c Test) were requested. Patients whose HbA1c level was above $7.5 \%$, alcoholic, drug abuse, poor oral hygiene and parafunctional habits like (Bruxism) were excluded from this study. 
Cone Beam CTs were taken for all patients to show the height and width of bone in the edentulous areas, the position of the mental foramen, maxillary sinuses, inferior alveolar canal and to check for any undetectable pathology or bone abnormality. An informed consent approved by the ethics committee was signed by each patient after discussing the treatment plan with them and prior to initiation of treatment.

Patients were randomly and equally distributed into two main groups (thirty each) according to internal hexagon or conical hybrid connection: Group (1): were patients receiving internal hexagon implants (Legacy $^{\mathrm{TM}}$ 2, Implant Direct) while group (2): were patients receiving conical hybrid connection implants (AnyRidge; MEGAGEN). Each group was subdivided into 3 subgroups (ten each) according to the bony position of implant placement (subcrestal, crestal, supracrestal). Implants were placed surgically, after three to six months, the implants were re-exposed and gingival healing formers were screwed. After two weeks, gingival formers were removed and impressions were taken using the direct pick up impression transfers then corresponding abutments were screwed into implants using digital torque gauge. Patients were then recalled to deliver their CADCAM restorations. All patients were then scheduled for clinical and radiographic follow-up visits (Figures 1, 2, $3 \& 4$ ).

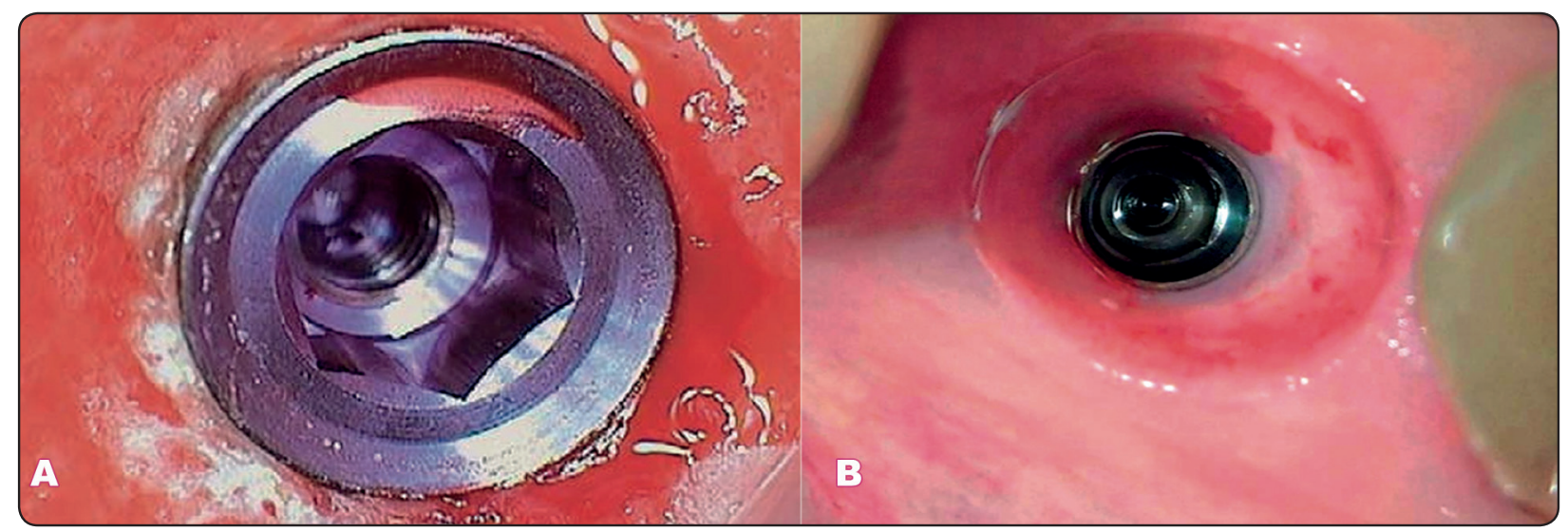

Fig. (1): Showing (A) Internal hex connection and (B) Conical Hybrid connection

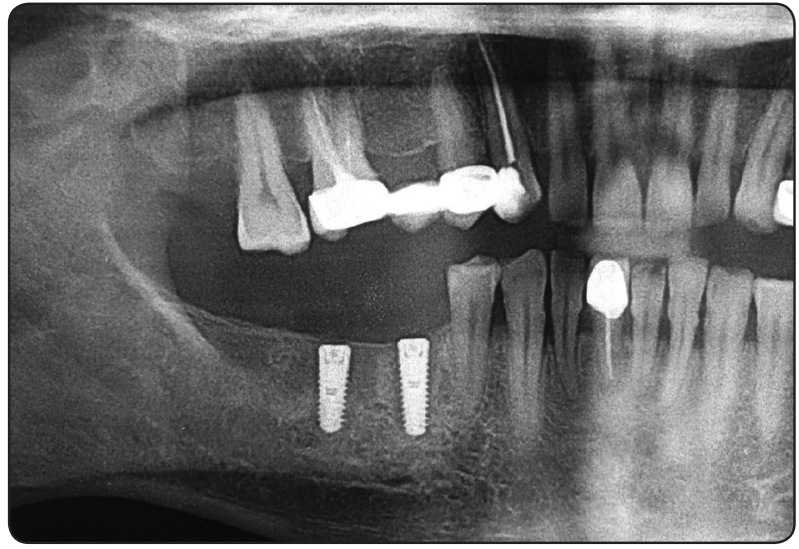

Fig. (2): Showing internal hexagon implants Legacy $^{\mathrm{TM}} 2$, Implant Direct) at different crestal positions

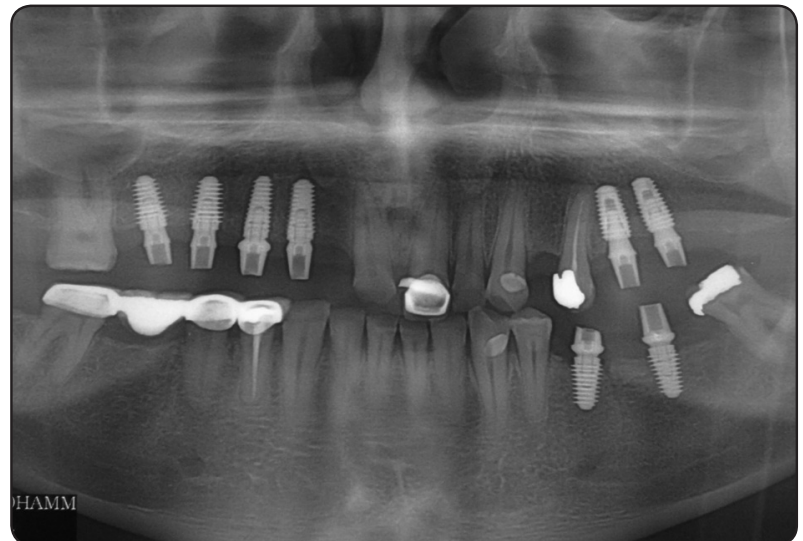

Fig. (3): Showing conical hybrid implants (AnyRidge; MEGAGEN) at different crestal positions 


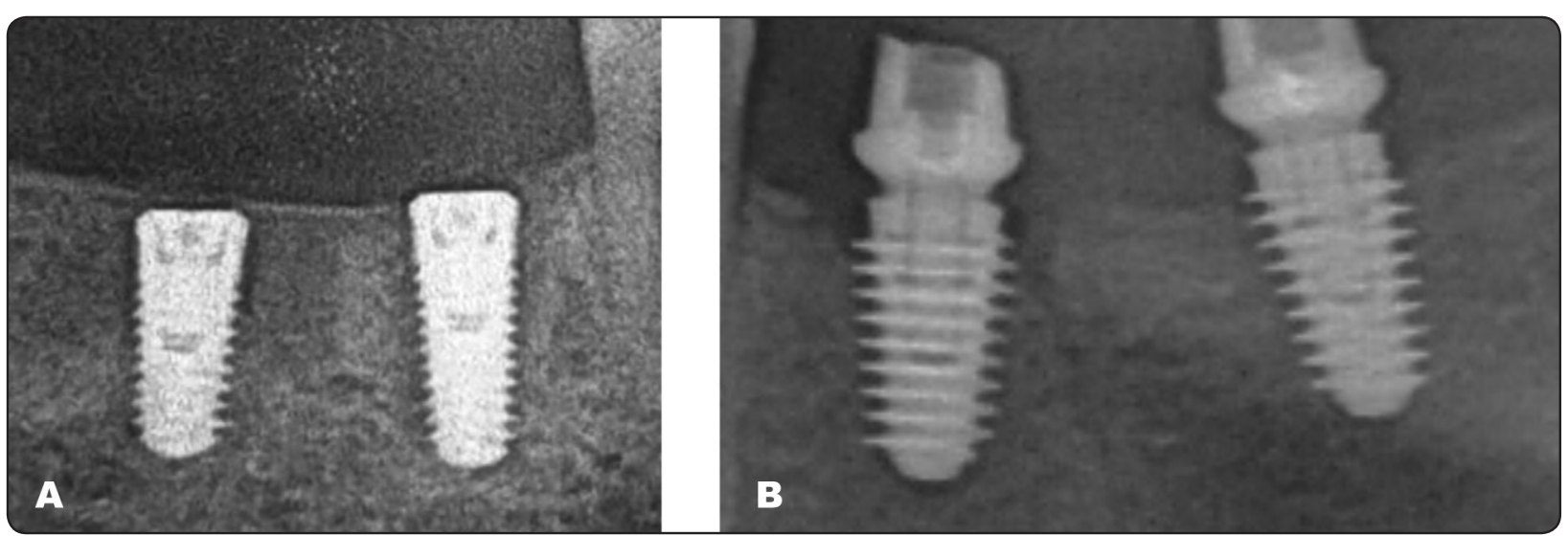

Fig. (4): Showing (A) Periapical X ray for internal hexagon implants (Legacy ${ }^{\mathrm{TM}}$ 2, Implant Direct) at different crestal positions and (B) Periapical X ray for conical hybrid implants (AnyRidge; MEGAGEN) at different crestal positions

Patients were evaluated radiographically at baseline (restoration delivery) and at 6, 12, 24 and 36 months after restoration delivery as follows:

Periapical X-ray films were used to measure the marginal bone loss around the implants. The long cone paralleling technique using the Rinn XCP instrument (Rinn Co. Dentsply division) was used. It included the use of standardized periapical radiographs to detect changes in alveolar bone surrounding the implants during the follow-up period. The standardized periapical radiographs were taken by the Xerograph Coping Process holder with a personalized bite registration record, made from putty rubber base impression material for extension cone $(35 \mathrm{~cm})$ paralleling technique. Every X-ray film was inserted into a slot in the bite-block. To ensure accurate repositioning of the film every time the radiograph was taken, the putty rubber base impression material (Express XT VPS, 3M ESPE) was folded around the bite-block, then a bite registration was obtained for each film in closed mouth position, the putty bite-block with the occlusal registration was kept aside for the followup recall visits. All radiographs were exposed using ultra speed periapical film (Kodak, Paris, France) with X-ray grid and X-ray unit set at $70 \mathrm{KV}$ and 10 $\mathrm{mA}$. With similar exposure times, the radiographs were developed under standardized condition using automatic process. The digital image was then saved in an uncompressed format on the patient file. The stored images of each patient were then interpreted at the end of the follow-up period.

Repeatable standardized periapical radiographs were made for each implant to measure the mesial and distal bone heights. The measurements were made from the base of the implant to the most coronal point of bone adjacent to the implant surface.

The reference point for measurements was the apex of the fixture. The distance was measured to the nearest $0.01 \mathrm{~mm}$. These measurements were done using an analysis software program (Adobe Photoshop, Adobe Systems Incorporated, San Jose, CA, USA). The actual implant length served as a standard to calculate the bone height, calculations were made according to the following formula:

\section{$\mathrm{CBL}=\mathrm{IL} * \mathrm{BR} / \mathrm{MIL}$}

Where $\mathbf{C B L}$ is the calculated bone resorption, IL: Actual implant length, BR: measured bone resorption (mean mesial and distal) and MIL: measured implant length.

\section{Data analysis}

Radiographic data were tabulated for each individual and group. Summary statistics (mean, 
standard deviation) were calculated and also tabulated, data were statistically analyzed using t student test and ANOVA test followed by Tukey's test at 0.05 significance level.

\section{RESULTS}

Sixty implants were positioned in partially edentulous male patients in this study. During the observation period, no implants were lost nor did fractures occur.

Table (1) lists the results of the t student test analysis for marginal bone loss at different periods of follow-up. After 6 months from prosthesis insertion, mean \pm standard deviation (SD) of marginal bone loss scores of group I patients was $(0.91 \pm 5.3)$, while mean \pm standard deviation (SD) of marginal bone loss scores of group II patients was $(0.61 \pm$ 7.46). During the follow-up period there was a nonsignificant statistical increase of the marginal bone loss scores $(\mathrm{P}<0.05)$ between the two groups.

However with the ANOVA test analysis for marginal bone loss at different periods of followup, there were statistical significant differences between the position groups and the crestal position group showed the highest values of peri-implant bone loss after three years of prostheses insertion. With Tukey's test there were statistically significant differences between sub crestal and crestal position groups and also between sub crestal and Supra crestal position groups, while no statistical significant difference was found between crestal and supra crestal position groups at different follow up periods (Table 2).

From table $1 \& 2$, the conical hybrid subcrestal group showing the lowest values of peri-implant bone loss after three years of prostheses insertion.

TABLE (1): Results of t Student test for marginal bone loss at different follow up periods.

\begin{tabular}{|c|c|c|c|c|}
\hline $\begin{array}{c}\text { Period of follow } \\
\text { up }\end{array}$ & Group I & Group II & \multirow{2}{*}{$\mathbf{p}$} & $\mathbf{p}$ \\
\cline { 2 - 4 } (Inter Hex) & (Con Hyp) & & \\
\hline After 6 months: & & & & \\
\hline Mean \pm S.D. & $0.91 \pm 5.3$ & $0.61 \pm 7.46$ & 2.48 & 0.08 \\
\hline After 12 months: & & & & \\
\hline Mean \pm S.D. & $1.2 \pm 0.66$ & $1 \pm 3.64$ & 4.03 & 0.126 \\
\hline After 24 months: & & & & \\
\hline Mean \pm S.D. & $1.24 \pm 0.064$ & $1.05 \pm 0.025$ & 6.04 & 0.182 \\
\hline After 36 months: & & & & \\
\hline Mean \pm S.D. & $1.34 \pm 0.124$ & $1.11 \pm 0.129$ & 4.34 & 0.324 \\
\hline
\end{tabular}

*Significance: $P<0.05$

TABLE (2): Results of the ANOVA test for marginal bone loss at different follow up periods.

\begin{tabular}{|c|c|c|c|c|c|c|c|c|c|}
\hline \multirow{2}{*}{ Period of follow up } & \multicolumn{3}{c|}{ Sub Groups } & \multicolumn{2}{c|}{ ANOVA } & \multicolumn{3}{c|}{ TUKEY'S Test } \\
\cline { 3 - 10 } & Sub Crestal & Crestal & $\begin{array}{c}\text { Supra } \\
\text { Crestal }\end{array}$ & F & P-value & $\begin{array}{c}\text { Sub } \\
\text { C\&C }\end{array}$ & $\begin{array}{c}\text { Sub C \& } \\
\text { Supra C }\end{array}$ & $\begin{array}{c}\text { C\& } \\
\text { Supra C }\end{array}$ \\
\hline After 6 months & Mean \pm SD & $0.35 \pm 0.48$ & $1.1 \pm 0.12$ & $0.8 \pm 0.41$ & 20.7 & $0.0001 *$ & $0.0001^{*}$ & $0.001^{*}$ & 0.124 \\
\hline After 12 months & Mean \pm SD & $0.91 \pm 0.39$ & $1.33 \pm 0.13$ & $1.18 \pm 0.13$ & 14.06 & $0.0001 *$ & $0.0001^{*}$ & $0.001^{*}$ & 0.323 \\
\hline After 24 months & Mean \pm SD & $1.14 \pm 0.11$ & $1.5 \pm 0.17$ & $1.34 \pm 0.13$ & 30.12 & $0.0001 *$ & $0.0001^{*}$ & $0.001^{*}$ & 0.144 \\
\hline After 36 months & Mean \pm SD & $1.2 \pm 0.16$ & $1.6 \pm 0.16$ & $1.5 \pm 0.15$ & 38.07 & $0.0001 *$ & $0.0001^{*}$ & $0.001^{*}$ & 0.114 \\
\hline
\end{tabular}

*Significance: $P<0.05$ 


\section{DISCUSSION}

Although Albrektsson et al, ${ }^{23}$ declared that a dental implant is considered successful if periimplant crestal bone loss is less than $1.5 \mathrm{~mm}$ during the first year after implant placement and less than $0.2 \mathrm{~mm}$ annually; it is strictly recommended that crestal bone height around dental implants should be maintained. ${ }^{24}$ So, once osseointegration has been gained, the connection system plays a major role in the crestal bone level maintenance. ${ }^{25}$

In this study, measurements of crestal bone levels were not calculated before loading to exclude factors that could theoretically causes changes in crestal bone during healing period, including surgical trauma of the two surgical phases and periimplantitis. ${ }^{3}$

In the current study, although no statistical significant differences were found between conical hybrid and internal connection main groups; the mean crestal bone loss of the conical hybrid main group was less than that of the internal hexagon one. This matches the conclusions of previous studies ${ }^{26,27}$ and opposite to suggestions that the implantabutment connection appears to have a significant effect on crestal bone level around implants. . $2,28,29^{2}$

Although the hybrid connection or specifically the Morse taper design proved to be superior in decreasing microgap formation and prosthetic abutment stability because of the internal repositioned implant-abutment junction which make the bacteria away from the adjacent crestal bone ${ }^{30,31}$; the non- significant differences can be explained as the internal hexagon connection can reduce probability of micro-movement during loading similar to conical hybrid design. ${ }^{32}$

In this study, subcrestal implant positioning resulted in significant less crestal bone resorption than supracrestal and crestal positioning. This matched the results of previous studies ${ }^{19-22,33,34}$ and opposite to others..$^{17,18,35,36}$
This advantageous significant crestal bone preservation was explained that the exposed rough surface around subcrestal implants are less than that in case of crestal or supracrestal implants. In another meaning; the immediate action of bone remodeling around subcrestal implants after surgically inserted will maintain their surface unexposed. ${ }^{37}$

The least amount of crestal bone resorption in this study was for the subgroup of conical hybrid and subcrestal surgical position, beside the previously mentioned explanations for this result, it was previously concluded that this combination may have a synergetic effect on preservation of crestal bone around implants. ${ }^{38}$

\section{CONCLUSIONS}

Within the limitations of this study; conical hybrid implant abutment connection showed less crestal bone resorption around implants than internal hexagon implant abutment connection in any position of surgical placement. Subcrestal implant placement showed the less crestal bone resorption followed by supracrestal. Crestal implant positioning should be avoided whenever possible.

\section{Conflict of interest}

The Authors declare no conflict of interest and they have full control of all primary data.

\section{REFERENCES}

1. Branemark, P.I., Zarb, G. \& Albrektsson, T. Tissue-Integrated Prostheses. Osseointegration in Clinical Dentistry, 1985; 1st edition, 11-76. Chicago, IL: Quintessence Publishing Co.

2. Freitas-Júnior AC, Almeida EO, Bonfante EA, Silva NR, Coelho PG Reliability and failure modes of internal conical dental implant connections. Clin Oral Implants Res 2013; 24:197-202.

3. Fickl S, Zuhr O, Stein JM, Hürzeler MB. Peri-implant bone level around implants with platform-switched abutments. Int J Oral Maxillofac Implants. 2010;25:577-81 . 
4. Merz, B.R., Hunenbart, S. \& Belser, U.C. Mechanics of the implant-abutment connection: an 8-degree taper compared to a butt joint connection. Int J Oral Maxillofac Implants 2000; 15: 519-26

5. Finger, I.M., Castellon, P., Block, M. \& Elian, N. The evolution of external and internal implant/abutment connections. Practical Procedures and Aesthetic Dent 2003; 15:625-32.

6. Wiskott, H.W., Jaquet, R., Scherrer, S.S. \& Belser, U.C. Resistance of internal-connection implant connectors under rotational fatigue loading. The Int J Oral Maxillofac Implants 2007; 22: 249-57.

7. Bernardes, S.R., de Araujo, C.A., Neto, A.J., Simamoto Junior, P. \& das Neves, F.D. Photoelastic analysis of stress patterns from different implant-abutment interfaces. Int J Oral Maxillofac Implants 2009; 24: 781-9.

8. Coppede, A.R., Bersani, E., de Mattos, G., Rodrigues, R.C., Sartori, I.A. \& Ribeiro, R.F. Fracture resistance of the implant-abutment connection in implants with internal hex and internal conical connections under oblique compressive loading: an in vitro study. Int J Prosthodont 2009; 22: $283-6$.

9. Tsuge, T. \& Hagiwara, Y. Influence of lateral-oblique cyclic loading on abutment screw loosening of internal and external hexagon implants. Dent Mat J 2009; 28: 373-81.

10. Gracis S, Michalakis K, Vigolo P, Von Steyern P, Zwahlen M, Sailer I, Internal vs. external connections for abutments/reconstructions: a systematic review. Clin Oral Implants Res 2012; 23 (Suppl. 6): 202-16.

11. Schwarz F, Hegewald A, Becker J. Impact of implant-abutment connection and positioning of the machined collar/ microgap on crestal bone level changes: a systematic review. Clin Oral Implants Res 2014; 25:417-25.

12. Balik A, Karatas M, Keskin H. Effects of different abutment connection designs on the stress distribution around five different implants: a 3-dimensional finite element analysis. J Oral Implantol 2012;38 Spec:491-6.

13. Novaes AB, Barros RR, Muglia VA, Borges GJ. Influence of interimplant distances and placement depth on papilla formation and crestal resorption: A clinical and radiographic study in dogs. J Oral Implantol 2009;35:18-27.

14. Chou HY, Mu“ftu“ S, Bozkaya D. Combined effects of implant insertion depth and alveolar bone quality on periimplant bone strain induced by a wide-diameter, short im- plant and a narrow-diameter, long implant. J Prosthet Dent 2010;104:293-300.

15. Broggini N, McManus LM, Hermann JS, et al. Peri-implant inflammation defined by the implant abutment interface. J Dent Res 2006;85:473-8.

16. Boynuegri AD, Yalim M, Nemli SK, Erguder BI, Gokalp P. Effect of different localizations of microgap on clinical parameters and inflammatory cytokines in peri-implant crevicular fluid: A prospective comparative study. Clin Oral Investig 2012;16:353-61.

17. Jung RE, Jones AA, Higginbottom FL, et al. The influence of non-matching implant and abutment diameters on radiographic crestal bone levels in dogs. J Periodontol 2008; 79: 260-70.

18. Van Eekeren PJ, Tahmaseb A, Wismeijer D. Crestal Bone Changes Around Implants with Implant-Abutment Connections at Epicrestal Level or Above: Systematic Review and Meta-Analysis. Int J Oral Maxillofac Implants. 2016 Jan-Feb;31(1):119-24.

19. Aimetti M, Ferrarotti F, Mariani GM, Ghelardoni C, Romano F. Soft tissue and crestal bone changes around implants with platform-switched abutments placed nonsubmerged at subcrestal position: a 2-year clinical and radiographic evaluation. Int $\mathbf{J}$ Oral Maxillofac Implants. 2015;30(6):1369-77.

20. Barros RR, Novaes AB Jr, Muglia VA, Iezzi G, Piattelli A. Influence of inter-implant distances and placement depth on peri-implant bone remodeling of adjacent and immediately loaded Morse cone connection implants: A histomorphometric study in dogs. Clin Oral Implants Res 2010; 21: $371-8$.

21. Calvo-Guirado JL, López-López PJ, Mate Sanchez JE, Gargallo Albiol J, Velasco Ortega E, Delgado Ruiz R. Crestal bone loss related to immediate implants in crestal and subcrestal position: a pilot study in dogs. Clin Oral Implants Res. 2014; 25(11):1286-94

22. Valles C, Rodríguez-Ciurana X, Clementini M, Baglivo M, Paniagua B, Nart J. Influence of Subcrestal Implant Placement Compared With Equicrestal Position on the Peri-Implant Hard and Soft Tissues Around PlatformSwitched Implants: A Systematic Review and Meta-Analysis. Clin Oral Investig. 2018;22(2):555-70.

23. Albrektsson T, Zarb G, Worthington P, Eriksson AR. The long-term efficacy of currently used dental implants: a review and proposed criteria of success. Int J Oral Maxillofac Implants 1986; 1:11-25. 
24. Buser D, Ingimarsson S, Dula K, Lussi A, Hirt HP, Belser UC. Long-term stability of osseointegrated implants in augmented bone: a 5-year prospective study in partially edentulous patients. Int J Periodontics Rest Dent 2002; 22:109-17.

25. Almeida E, Freitas A, Bonfante E, Marotta L, Silva N, Coelho P. Mechanical testing of implant-supported anterior crowns with different implant/abutment connections. Int J Oral Maxillofac Implants 2013; 28:103-8.

26. Lin M, Shen Y, Huang H, Hsu J, Fuh L.A Retrospective Study of Implant-Abutment Connections on Crestal Bone Level. J Dent Res 2013; 92:202-7.

27. Herekar M, Patil A, Sethi M, Ahmad T, Fernandes A, Patil V. Effect of implant abutment connection on marginal bone level alterations: a systematic literature review. Clin Oral Implants Res 2014; 25 (Suppl. 10) Poster.

28. Peñarrocha-Diago MA, Flichy-Fernández AJ, AlonsoGonzález R, Peñarrocha-Oltra D, Balaguer-Martínez J, Peñarrocha-Diago M. Influence of implant neck design and implant-abutment connection type on peri-implant health. Radiological study. Clin Oral Implants Res 2013; 24(11):1192-200

29. Melo LA, Souza MBC, Barbosa GAS, Carreiro ADFP. Peri-Implant Bone Loss of External Hexagon and Morse Taper in Patients Wearing Immediately Loaded Overdentures. Braz Dent J. 2017;28(6):694-8.

30. Canullo L, Micarelli C, Lembo-Fazio L, Iannello G, Clementini M. Microscopical and microbiologic characterization of customized titanium abutments after different cleaning procedures. Clin. Oral Impl. Res. 2014;25:328-36.

31. Schmitt CM, Nogueira-Filho G, Tenenbaum HC, Lai JY, Brito C, Döring H, Nonhoff J. Performance of conical abutment (Morse Taper) connection implants: a systematic review. J Biomed Mater Res A. 2014;102:552-74.
32. Jaworski ME, Melo AC, Picheth CM, Sartori IA. Analysis of the bacterial seal at the implant-abutment interface in external hexagon and Morse taper-connection implants: an in vitro study using a new methodology. Int J Oral Maxillofac Implants 2012; 27:1091-95

33. Degidi M, Perrotti V, Shibli JA, Novaes AB, Piattelli A, Iezzi G. Equicrestal and subcrestal dental implants: A histologic and histomorphometric evaluation of nine retrieved human implants. Journal of Periodontology 2011;82:708-15

34. Donovan R, Fetner A, Koutouzis T, Lundgren T. Crestal bone changes around implants with reduced abutment diameter placed non-submerged and at subcrestal positions: a 1-year radiographic evaluation. J Periodontol. 2010; $81: 428-34$

35. Cesaretti G, Lang NP, Salata LA, Schweikert MT, Gutierrez Hernandez ME, Botticelli D. Sub-crestal positioning of implants results in higher bony crest resorption: an experimental study in dogs. Clin Oral Impl Res. 2015;26:1355-60.

36. Hänggi MP, Hänggi DC, Schoolfield JD, Meyer J, Cochran DL, Hermann JS. Crestal bone changes around titanium implants. Part I: A retrospective radiographic evaluation in humans comparing two non-submerged implant designs with different machined collar lengths. J Periodontol 2005;76:791-802.

37. Pellicer-Chover H, Díaz-Sanchez M, Soto-Peñaloza D, Peñarrocha-Diago M, Canullo L, Peñarrocha-Oltra D. Impact of crestal and subcrestal implant placement upon changes in marginal peri-implant bone level. A systematic review. Med Oral Patol Oral Cir Bucal. 2019;5:673-83.

38. Veis A, Parissis N, Tsirlis A, Papadeli C, Marinis G, Zogakis A. Evaluation of peri-implant marginal bone loss using modified abutment connections at various crestal level placements. Int J Periodont Rest Dent. 2010; 6:609-17. 